University of Nebraska - Lincoln

DigitalCommons@University of Nebraska - Lincoln

8-1-1997

\title{
LDC Agriculture: Non-parametric Malmquist Productivity Indexes
}

Lilyan E. Fulginiti

University of Nebraska-Lincoln, Ifulginiti1@unl.edu

Richard K. Perrin

University of Nebraska-Lincoln, rperrin@unl.edu

Follow this and additional works at: https://digitalcommons.unl.edu/ageconfacpub

Part of the Agricultural and Resource Economics Commons

Fulginiti, Lilyan E. and Perrin, Richard K., "LDC Agriculture: Non-parametric Malmquist Productivity Indexes" (1997). Faculty Publications: Agricultural Economics. 11.

https://digitalcommons.unl.edu/ageconfacpub/11

This Article is brought to you for free and open access by the Agricultural Economics Department at DigitalCommons@University of Nebraska - Lincoln. It has been accepted for inclusion in Faculty Publications: Agricultural Economics by an authorized administrator of DigitalCommons@University of Nebraska - Lincoln. 


\title{
LDC agriculture: Nonparametric Malmquist productivity indexes ${ }^{1}$
}

\author{
Lilyan E. Fulginiti ${ }^{*}$, Richard K. Perrin
}

Department of Agricultural Economics, University of Nebraska, Lincoln, NE, 68583-0922, USA

\begin{abstract}
This paper examines changes in agricultural productivity in 18 developing countries over the period 1961-1985. We use the nonparametric, output-based Malmquist index to examine whether the results from such an approach confirm results from other methods that have indicated declining agricultural productivity in less developed countries (LDCs). The results confirm previous findings, indicating that at least half of these countries have experienced productivity declines in agriculture. We also found that those countries that tax agriculture most heavily had the most negative rates of productivity change. (C) 1997 Elsevier Science B.V.
\end{abstract}

JEL classification: O4 Economic growth and aggregate productivity; Q1 Agriculture

Keywords: Agricultural productivity; Nonparametric; Malmquist; Taxes

\section{Introduction}

In the economics literature, aggregate productivity refers to the amount of output obtained from given levels of inputs in an economy or a sector. It is an important topic of study because productivity is one of two fundamental sources of larger income streams; the other being savings, which permit more inputs to be

\footnotetext{
" Corresponding author. Tel.: 4024720651; fax: 4024723460; e-mail: lfulginiti@unl.edu

${ }^{1}$ Journal Paper No. J-16527 of the Iowa Agriculture and Home Economics Experiment Station, Ames, Iowa. Project No. 2998. 
employed. Moreover, productivity rather than additional inputs has been the real engine driving growth in agricultural output in the developed world, inasmuch as changes in output from decade to decade in this century have borne little or no relationship to changes in inputs. Schultz (1956) first noted this phenomenon at midcentury, and it has been even more pronounced since then. The analysis to follow will focus on measuring productivity in the agricultural sectors of less developed countries (LDCs), where, contrary to the case of the developed world, previous studies suggest that agricultural productivity is declining.

There is a substantial body of literature measuring multifactor agricultural productivity in the U.S. (Jorgenson et al., 1987; Ball, 1985; Capalbo, 1988; Chavas and Cox, 1990; Bureau et al., 1995; Trueblood and Ruttan, 1995). These studies used a variety of approaches including estimation of rates of shifts in production and cost functions, nonparametric methods (to be discussed in more detail later) and indexing approaches. ${ }^{2}$ On the other hand, so far as we are aware, the only studies of multifactor agricultural productivity in LDCs are the one by Fulginiti and Perrin (1993) and those by Kawagoe et al. (1985), by Lau and Yotopoulos (1989) and by Kawagoe and Hayami (1985). ${ }^{3}$ Fulginiti and Perrin (1993), examining essentially the same LDC data set as in the present study, did not report direct measures of productivity change, but the results from their Cobb-Douglas production specification (reported in the present study) showed technological regression for 14 of 18 countries. Kawagoe et al. (1985), using data for 1960, 1970 and 1980 in 21 developed countries (DCs) and 22 LDCs, estimated cross-country production functions with dummy variables for 1970 and 1980 . They found technological regression during both decades for the LDCs, but technological progress in the DCs. Kawagoe and Hayami (1985) found similar results in that data set, using an indirect production function approach that is similar to the indexing approach except that input shares are estimated by using marginal productivities from an aggregate production function instead of prices. Lau and Yotopoulos (1989) criticized the functional form used in that study and used the same data with a translog functional form and country effects. Their results also showed negative productivity for LDCs during the 1970 s but an increase during the 1960s.

Without exception, the studies of developed-country agriculture have shown substantial productivity increases, whereas the results for LDCs have consistently

\footnotetext{
${ }^{2}$ Indexing approaches compare the share-weighted average rate of change of outputs with the share-weighted average rate of change of inputs. The ratio of these rates is a measure of the rate of change in aggregate multifactor productivity. The difference between the two average rates of change is the Solow residual, and under appropriate assumptions such as constant returns to scale, no uncertainty, technological efficiency and perfect markets, it is a measure of the rate of technological change.

${ }^{3}$ Hayami and Ruttan (1985) and Kawagoe et al. (1985) also report a number of partial productivity measures (land productivity and labor productivity) for LDCs, but these reveal little about multifactor productivity.
} 
shown productivity declines, even in those LDCs where green revolution of varieties of wheat and rice have been widely adopted. This discrepancy is surprising and puzzling. ${ }^{4}$ It seems unlikely that farmers of these countries were persuaded or forced to adopt techniques that reduced productivity on such a wide scale. It is possible that the new varieties permitted them to move out a decreasing returns-to-scale production function, reducing productivity by an undetected scale effect, ${ }^{5}$ but previous studies have not revealed decreasing returns to scale in the aggregate, and this did not happen in the DCs. It is also possible, as suggested elsewhere (Fulginiti and Perrin, 1993), that price policies or other interferences with the agricultural sector had a sufficiently chilling effect on incentives as to stifle potential productivity gains.

But it is also possible that the methods and data previously used have inaccurately portrayed the LDC agricultural sectors as regressing in productivity. Before explanations of the declining productivity phenomenon are pressed further, it is useful to examine the robustness of the result to alternative measurement techniques, and that is the purpose of the present study. It is not feasible to employ indexing approaches in these countries, because of data difficulties with respect to prices of inputs. ${ }^{6}$ Here the alternative we employ is the nonparametric approach pioneered by Färe et al. (1992), which we use to examine the performance of the agricultural sectors in a set of eighteen LDCs. The approach is a significant departure from the production function approach, with the disadvantage that it has no stochastic component and thus provides only point estimates of productivity gains (a characteristic shared with other indexing approaches). Its advantages are that is it is free from errors resulting from misspecification of functional form, and that it relaxes the assumption of technical efficiency, thus allowing the partitioning of productivity changes into efficiency and technical change components.

\section{Malmquist productivity indexes}

One quantity-based conceptual approach to measuring productivity change is to compare observed change in output with the imputed change in output that would

\footnotetext{
${ }^{4}$ It would not have been so surprising to Ricardo and other early classical economists, who did not anticipate significant changes in productivity, and thus believed that demographic pressure on limited natural resources, specifically land, would continually threaten growth in agricultural productivity.

${ }^{5}$ Diamond et al. (1978) and Sato (1980) have shown that in the absence of prior hypotheses concerning the structure of technical change, technical progress is undistinguishable from scale effects.

${ }^{6}$ Input prices are required to calculate the shares needed for weighted values in the index approach, and the validity of the indexes as measures of technological change requires that those prices reflect the marginal value products of the inputs. Time series data on land rental rates are nonexistent for LDCs, the quality of data on other input prices is generally suspect, and frictions of various types often prevent LDC farmers from adjusting input levels to the point that marginal value product could equal price.
} 
have been possible from the observed input changes, the imputation being based on the production possibilities set for either the current or the subsequent period. Since in the multiple-output, multiple-input situation the concept of a production function is not operable for such a comparison, Caves et al. (1982) proposed using the ratio of two distance functions to implement this measure of productivity change. ${ }^{7}$ Since two Malmquist ratios are available for any time interval (depending on whether the reference technology is that of the initial period or the subsequent period), Färe et al. (1992, hereafter FGLR) proposed the use of the geometric mean of the two. This Malmquist index has the additional feature that it can be decomposed into the product of a pure efficiency change component, a scale efficiency change component and a technological change component. In terms of data requirements, the Malmquist index requires only quantity data whereas the indexing approaches to productivity measurement require data on prices as well as quantities of inputs and outputs.

In this paper we closely follow Färe et al. (1994a,b) in defining and decomposing the output-based Malmquist index of productivity change. For each time period $t=1, \ldots, T$, the production technology $S^{t}$ is defined as the set of all feasible input $\left[x^{t}=\left(x^{1}, \ldots, x^{N}\right)\right]$ and output pairs $\left[y^{t}=\left(y^{1}, \ldots, y^{M}\right)\right]$. We assume that the set $S^{t}$ is nonempty, closed and convex and that both inputs and outputs are freely disposable. The output distance function at time $t$ is defined as

$$
D^{t}\left(x^{t}, y^{t}\right)=\inf \left\{\theta:\left(x^{t}, \frac{1}{\theta} y^{t}\right) \in S^{t}\right\} .
$$

In words, the distance $\theta$ is the ratio of the current output basket to the maximum achievable multiple of that basket given the current level of inputs. Note that $D^{t}\left(x^{t}, y^{t}\right)=1$ if and only if $\left(x^{t}, y^{t}\right)$ is on the boundary or frontier of technology, and $D^{t}\left(x^{t}, y^{t}\right) \leq 1$ if and only if $\left(x^{t}, y^{t}\right) \in S^{t}$. These concepts can be illustrated for the case of a single output and single input as in Fig. 1. Here the boundary of the technology is represented as $S_{\mathrm{CRS}}^{t}$ for a constant returns-to-scale (CRS) technology, or $S_{\mathrm{VRS}}^{t}$ for a variable returns-to-scale (VRS) technology. Observed production at $t,\left(x^{t}, y^{t}\right)$ is interior to the period- $t$ boundary. The distance function $D^{t}\left(x^{t}, y^{t}\right)$ is the ratio of observed output to maximum output attainable for input $x^{t}$ with year $t$ technology, or OA/OB (for CRS technology). In Fig. 1 this distance is less than one, and it is said that the observed point is not Farrell efficient. The distance function $D^{t+1}\left(x^{t}, y^{t}\right)$ relates observed output to the maximum attainable with year $t+1$ technology, or OA/OC.

In the multiple-output-multiple-input case, the notion of a production function is no longer adequate to describe the frontier, but the output distance function (Eq. (1)) nonetheless, completely characterizes the technology and the efficiency of any

\footnotetext{
${ }^{7}$ They named the index after Malmquist (1953) who had proposed constructing quantity indexes as ratios of distance functions.
} 


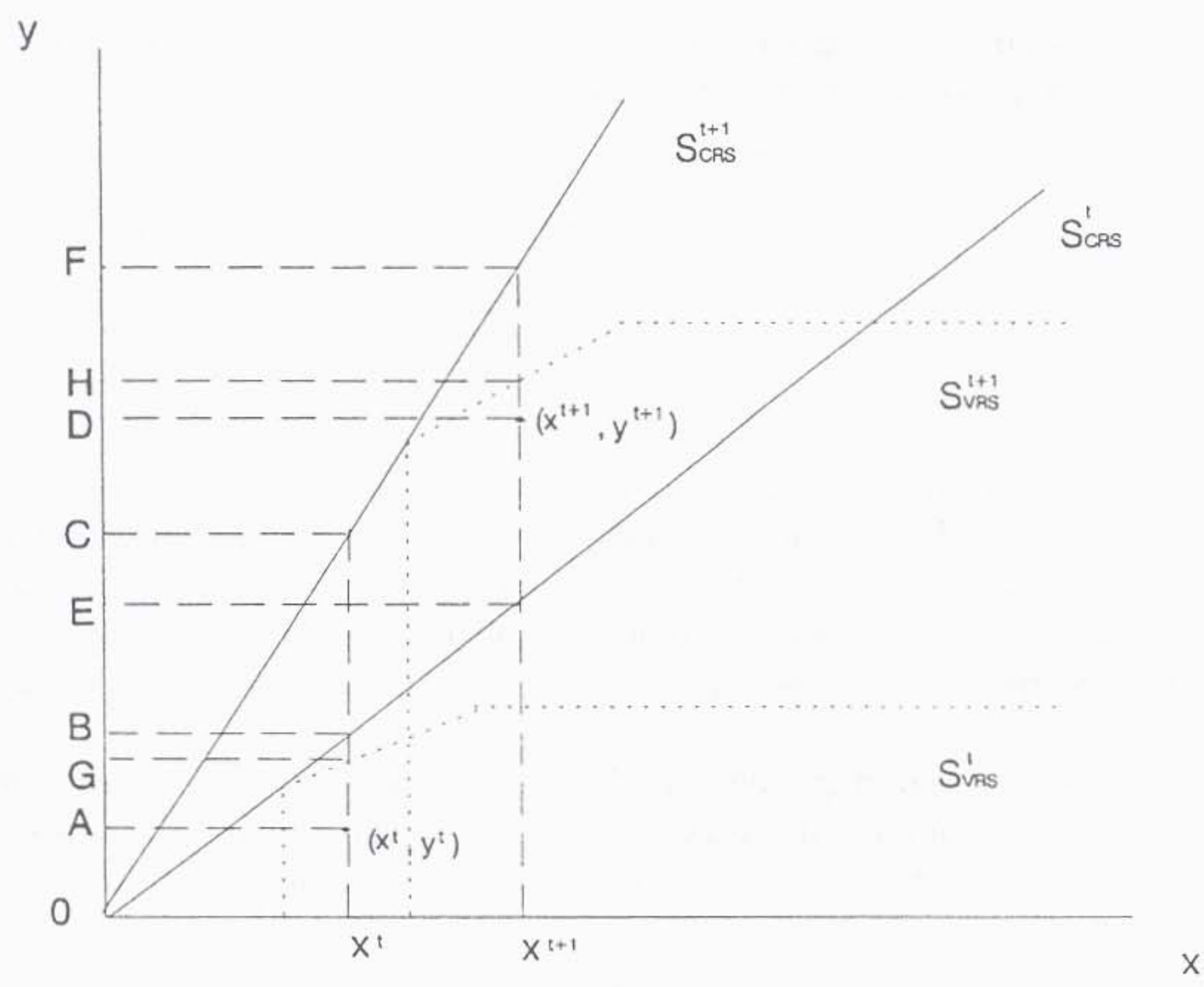

Fig. 1. Output distance functions.

input-output combination with respect to that technology. The Caves et al. (1982) version of the Malmquist productivity change can be expressed as ${ }^{8}$

$$
m^{t}=\frac{D^{t}\left(x^{t+1}, y^{t+1}\right)}{D^{t}\left(x^{t}, y^{t}\right)} \text {, or } m^{t+1}=\frac{D^{t+1}\left(x^{t+1}, y^{t+1}\right)}{D^{t+1}\left(x^{t}, y^{t}\right)} \text {. }
$$

The reference technology for the first ratio is $S^{t}$, and for the second it is $S^{t+1}$. If $m>1$, productivity has increased between $t$ and $t+1$. The FGLR index measures productivity change as the geometric mean of the above two indexes, or

$$
M\left(x^{t+1}, y^{t+1}, x^{t}, y^{t}\right)=\left[\frac{D^{t}\left(x^{t+1}, y^{t+1}\right)}{D^{t}\left(x^{t}, y^{t}\right)} \frac{D^{t+1}\left(x^{t+1}, y^{t+1}\right)}{D^{t+1}\left(x^{t}, y^{t}\right)}\right]^{\frac{1}{2}} \text {. }
$$

\footnotetext{
${ }^{8}$ This is an output-based index, since it uses output-based distance functions. They also propose an input-based productivity index.
} 
An index with value greater than unity reveals improved productivity. They note that this expression can be factored as

$$
\begin{aligned}
M\left(x^{t+1}, y^{t+1}, x^{t}, y^{t}\right)= & \frac{D^{t+1}\left(x^{t+1}, y^{t+1}\right)}{D^{t}\left(x^{t}, y^{t}\right)}\left[\frac{D^{t}\left(x^{t+1}, y^{t+1}\right)}{D^{t+1}\left(x^{t+1}, y^{t+1}\right)}\right. \\
& \left.\times \frac{D^{t}\left(x^{t}, y^{t}\right)}{D^{t+1}\left(x^{t}, y^{t}\right)}\right]^{\frac{1}{2}},
\end{aligned}
$$

where the ratio outside the brackets measures the change in relative efficiency (i.e., the change in the distance of observed production from maximum feasible production) between years $t$ and $t+1$, while the bracketed term measures the shift in technology between the two periods evaluated at $x^{t}$ and $x^{t+1}$ (or technical change). Efficiency and technical change indexes exceeding unity reflect gains in those components.

For the case of scalar output and input and a CRS technology, this index and its components can again be illustrated in Fig. 1, where technical advance has occurred. ${ }^{9}$ In terms of the distances along the $y$-axis, the index becomes

$$
\begin{aligned}
M\left(x^{x+1}, y^{x+1}, x^{t}, y^{t}\right) & =\frac{O D}{O F} \frac{O B}{O A}\left[\begin{array}{ll}
\frac{\frac{O D}{O E}}{O D} & \frac{\frac{O A}{O B}}{O A} \\
O C
\end{array}\right]^{1 / 2} \\
& =\frac{O D}{O F} \frac{O B}{O A}\left[\frac{O F}{O E} \frac{O C}{O B}\right]^{\frac{1}{2}}
\end{aligned}
$$

and in terms of the production function, it is

$$
M\left(x^{t+1}, y^{t+1}, x^{t}, y^{t}\right)=\frac{\frac{y^{t+1}}{f^{t+1}\left(x^{t+1}\right)}}{\frac{y^{t}}{f^{t}\left(x^{t}\right)}}\left[\frac{f^{t+1}\left(x^{t}\right)}{f^{t}\left(x^{t}\right)} \frac{f^{t+1}\left(x^{t+1}\right)}{f^{t}\left(x^{t+1}\right)}\right]^{\frac{1}{2}} .
$$

\footnotetext{
${ }^{9}$ This simple constant returns-to-scale case illustrates how the Malmquist index measures a country's productivity change. In Eq. (5), substitute $\mathrm{OF}=\alpha_{t+1} x^{t+1}, \mathrm{OB}=\alpha_{t} x^{t}, \mathrm{OE}=\alpha_{t} x^{t+1}$, and $\mathrm{OC}=\alpha_{t+1} x^{t}$, where the $\alpha$ 's represent average and marginal product for year $t$ technology. Rearranging and canceling out the $\alpha$ 's, the index becomes $M=\left(y^{t+1} / y^{t}\right) /\left(x^{t+1} / x^{t}\right)$, i.e., just the percentage change in output over percentage change in input relative to the past year. Other countries included in the analysis determine the $\alpha$ 's if this country is not on the frontier, but they are irrelevant to productivity measurement in this simple case since those $\alpha$ 's cancel out.
} 
Färe et al. (1994a) introduced an additional decomposition of the efficiency component of the index in Eq. (4) that allows identification of change in scale efficiency (a change in scale efficiency is the change in productivity resulting from a scale change that brings the economy closer to, or farther away from, the optimum scale of output as identified by a variable returns-to-scale technology). ${ }^{10}$ The efficiency change calculated under the assumption of constant returns-to-scale technology can be decomposed as follows:

$$
\begin{aligned}
\frac{D^{t+1}\left(x^{t+1}, y^{t+1}\right)_{\mathrm{CRS}}}{D^{t}\left(x^{t}, y^{t}\right)_{\mathrm{CRS}}}= & \frac{D^{t+1}\left(x^{t+1}, y^{t+1}\right)_{\mathrm{VRS}}}{D^{t}\left(x^{t}, y^{t}\right)_{\mathrm{VRS}}}\left[\frac{D^{t}\left(x^{t}, y^{t}\right)_{\mathrm{VRS}}}{D^{t}\left(x^{t}, y^{t}\right)_{\mathrm{CRS}}}\right. \\
& \left.\times \frac{D^{t+1}\left(x^{t+1}, y^{t+1}\right)_{\mathrm{CRS}}}{D^{t+1}\left(x^{t+1}, y^{t+1}\right)_{\mathrm{VRS}}}\right]
\end{aligned}
$$

CRS efficiency change $=$ Pure efficiency change $\times$ Scale efficiency change where CRS (VRS) indicates a distance measured under the assumption of constant (variable) returns-to-scale. The pure efficiency change (the first term on the right) measures change in technical efficiency under the assumption of a variable returns-to-scale technology. In terms of the distances along the $y$-axis in Fig. 1

$$
\text { Pure efficiency change }=\frac{\mathrm{OD}}{\mathrm{OH}} \frac{\mathrm{OG}}{\mathrm{OA}} \text {. }
$$

Scale efficiency in a given period captures the deviations between the variable returns technology and the constant returns technology at observed inputs. The scale change portion of efficiency (term in brackets on the right-hand side of Eq. (7)) then measures changes in efficiency due to a movement toward or away from the point of optimum scale. In Fig. 1 it is

$$
\text { Scale change }=\frac{\frac{\mathrm{OA}}{\mathrm{OG}} \frac{\mathrm{OD}}{\mathrm{OF}}}{\frac{\mathrm{OA}}{\mathrm{OB}} \frac{\mathrm{OD}}{\mathrm{OH}}}=\frac{\mathrm{OB}}{\mathrm{OG}} \frac{\mathrm{OH}}{\mathrm{OF}}=\frac{\frac{\mathrm{OH}}{\mathrm{OF}}}{\frac{\mathrm{OF}}{\mathrm{OB}}} .
$$

Improvements are denoted by values exceeding unity.

The index in Eq. (4) is applicable to either parametric or nonparametric representations of the technology. Caves et al. (1982) showed that under certain conditions Eq. (3) can be computed as the ratio of Tornqvist indexes of outputs and inputs. ${ }^{11}$ Färe and Grosskopf (1992) ${ }^{12}$ showed that the index may also be

\footnotetext{
${ }^{10}$ In the single-input-single-output case, the optimum scale can be defined as the scale of operation consistent with the highest average product.

${ }^{11}$ The underlying technology must be translog and all second-order terms must be identical over time. It also requires technical and allocative efficiency.

12 Their results were later extended by Balk (1993).
} 
calculated as a ratio of Fisher ideal indexes. Another alternative is to parametrically estimate the frontiers and then use these frontiers to obtain the Malmquist index for each observation. ${ }^{13}$ The nonparametric approaches employ programming techniques to identify the technology frontier and measure the distance to that frontier for each observation in the sample. ${ }^{14}$

In this paper we follow Färe et al. (1992, 1994a,b), by using an activity analysis approach to calculate productivity changes and decompose them into efficiency and technical-change components. In this approach, the convex hull of observed data is assumed to define the technology frontier. There are $k=1, \ldots, K$ countries using $n=1, \ldots, N$ inputs $x_{n}^{k t}$ at each time period $t=1, \ldots, T$. These inputs are used to produce $m=1, \ldots, M$ outputs $y_{m}^{k t}$. To calculate the productivity of country $k^{\prime}$ between $t$ and $t+1$ for a constant returns-to-scale technology, a linear programming problem is solved to evaluate $D^{t}\left(x^{t}, y^{t}\right), D^{t+1}\left(x^{t}, y^{t}\right)$, $D^{t}\left(x^{t+1}, y^{t+1}\right)$ and $D^{t+1}\left(x^{t+1}, y^{t+1}\right)$. Using $i$ and $i^{\prime}$ to index time, then for each country $k^{\prime}=1, \ldots, K$, we compute

$$
\begin{array}{cc}
{\left[D^{i}\left(x^{k^{\prime} i^{\prime}}, y^{k^{\prime} i^{\prime}}\right)\right]^{-1}=\max \theta^{k \prime}} & \\
\text { s.t. } \theta^{k \prime} y_{m}^{k^{\prime} i^{\prime}} \leq \sum_{k=1}^{K} z^{k i} y_{m}^{k i} & m=1, \ldots, M, \\
\sum_{k=1}^{K} z^{k i} x_{n}^{k i} \leq x_{n}^{k^{\prime} i^{\prime}}, & n=1, \ldots, N, \\
z^{k i} \geq 0, & k=1, \ldots, K .
\end{array}
$$

where $z^{k t}$ is an intensity variable indicating the intensity at which a particular activity is employed in constructing the frontier of the technology set. When $i=i^{\prime}=t$, the solution to this problem yields the value $\left[D^{t}\left(x^{k^{\prime} t}, y^{k^{\prime} t}\right)\right]^{-1}$. Since by construction of that problem all observations are feasible (all are elements of the current technology set $\left.S^{t}\right)$, then $D^{t}\left(x^{k^{\prime} t}, y^{k^{\prime} t}\right) \leq 1$. The computation of $D^{t+1}\left(x^{k^{\prime} t+1}, y^{k^{\prime} t+1}\right)$ is exactly the same, with $i=i^{\prime}=t+1$.

The other two distance functions used to construct the Malmquist index require information from two periods. $D^{t}\left(x^{k^{\prime} t+1}, y^{k^{\prime} t+1}\right)$ is computed as the solution to Eq. (10) with $i=t$ and $i^{\prime}=t+1$, and $D^{t+1}\left(x^{k^{\prime} t}, y^{k^{\prime} t}\right)$, is computed as the solution to Eq. (10) with $i=t+1$ and $i^{\prime}=t$. Given these four values, the FGLR index is calculated for each pair of years for each country using Eq. (3), and it is decomposed into the efficiency and technical-change components as indicated by Eq. (4).

To calculate the distance functions $D^{t+1}\left(x^{t+1}, y^{t+1}\right)_{\mathrm{VRS}}$ and $D^{t}\left(x^{t}, y^{t}\right)_{\mathrm{VRS}}$ under the assumption of variable returns-to-scale technology needed for the

\footnotetext{
${ }^{13}$ This approach could include econometric estimation of either deterministic or stochastic frontiers.

${ }^{14}$ This is also referred to as data envelopment analysis or activity analysis.
} 
decomposition in Eq. (7), the programming problem in Eq. (10) is subjected to the additional constraint that $\sum_{k=1}^{K} z^{k t}=1$.

\section{Data and Results}

This empirical study examines productivity changes in the agricultural sectors of 18 LDCs $(k=1, \ldots, 18)$ previously examined using a modified aggregate agricultural production function. This set of countries is of interest because it includes a wide range of geographic locations, income levels and agricultural policies. A data set of consistently measured, quantity-based variables is available for these countries over the period 1961-1985 (Elisiana et al., 1993), but the lack of price data for inputs has precluded using Tornqvist-type indexes to examine productivity changes. Not only is the Malmquist index feasible, but it provides nonparametric estimates of productivity change that can be compared with those implied by our previous parametric study. The data consist of one output ( $y=1$, aggregate agricultural output) and five inputs $(x=1, \ldots, 5$; land, labor, fertilizer, machinery and livestock). These are the same definitions of input variables as used in the Hayami and Ruttan series of studies, ${ }^{15}$ though the present data include a different set of countries, cover a longer time span and include annual observations. The more specific definitions of these variables are given below.

Output $(y)$ : Quantity of agricultural production in millions of 1979-81 'international' dollars. ${ }^{16}$

Land $\left(x_{1}\right)$ : Thousands of hectares of arable and permanent cropland and permanent pastures.

Livestock $\left(x_{2}\right)$ : Number of cow-equivalent livestock units as defined by Hayami and Ruttan (1985).

Machinery $\left(x_{3}\right)$ : Agricultural tractors and garden tractors (FAO) in thousands of horsepower units, aggregated according to the procedures of Hayami and Ruttan (1985).

Fertilizer $\left(x_{4}\right)$ : The sum of nitrogen, potash and phosphate content of various fertilizers consumed, measured in thousands of metric tons in nutrient units.

Labor $\left(x_{5}\right)$ : Thousands of participants in the economically active population in agriculture. ${ }^{17}$

\footnotetext{
${ }^{15}$ See Hayami and Ruttan $(1970,1985)$.

${ }^{16}$ This quantity index is obtained by multiplying the FAO agricultural production index for a country (a Laspeyres quantity index) by the 1980 value of agricultural production for that country, as reported by FAO in 'international' dollars. This scaling of the FAO quantity indexes of production is necessary to capture differences in scale of production across countries. The resulting output measure is a quantity index of agricultural production that is consistent across time and countries.

${ }^{17}$ This measure of agricultural labor input, also used in the other cross-country studies cited, is a crude one, uncorrected for hours worked and labor quality (education, experience, age, etc.).
} 
Table 1

Agricultural protection and growth of 18 countries

\begin{tabular}{lllc}
\hline Countries & Years & NPR $^{\mathrm{a}}(\%)$ & Production growth $^{\mathrm{b}}(\%)$ \\
\hline Argentina & $1961-1984$ & -40 & 2.1 \\
Brazil & $1969-1983$ & -13 & 3.8 \\
Chile & $1961-1983$ & -25 & 1.8 \\
Colombia & $1961-1983$ & -33 & 2.8 \\
Dominican R. & $1966-1985$ & -40 & 2.8 \\
Egypt & $1964-1984$ & -53 & 2.7 \\
Ghana & $1958-1976$ & -24 & 1.1 \\
Ivory Coast & $1961-1982$ & -53 & 5.2 \\
Korea & $1961-1984$ & 16 & 4.2 \\
Malaysia & $1961-1983$ & -18 & 3.3 \\
Morocco & $1963-1984$ & -34 & 4.0 \\
Pakistan & $1961-1984$ & -47 & 3.8 \\
Philippines & $1961-1982$ & -32 & 3.8 \\
Portugal & $1961-1983$ & -18 & -0.1 \\
Sri Lanka & $1961-1985$ & -49 & 2.1 \\
Thailand & $1961-1984$ & -41 & 4.7 \\
Turkey & $1961-1983$ & -36 & 2.8 \\
Zambia & $1966-1984$ & -53 & 2.2 \\
\hline
\end{tabular}

${ }^{a} \mathrm{NPR}=$ nominal protection rate $=($ domestic price $/$ border price $)-1$, adjusted for exchange rate misalignment and protection to industry.

${ }^{\mathrm{b}}$ Calculated from FAO production indexes.

The countries included are presented in Table 1 along with the growth rate of agricultural output for the period and the degree of taxation of the agricultural sector measured by nominal protection coefficients. Ivory Coast had the highest average annual growth of agricultural output and Portugal had the lowest, showing a contraction of agricultural output.

For each successive pair of years, we evaluate the four required distance functions by solving the linear programming problem of Eq. (10). A total of 1512 such linear programming problems were solved, under the restrictions of constant returns-to-scale and, alternately, variable returns-to-scale. These solution values are used to calculate the Malmquist productivity change index, the pure efficiency change index, the scale change index and the technical change index using Eqs. (4) and (7) for each successive pair of years for each country. Although all countries are presumed to share a common technology set, their rates of technical change can differ because each country is located near a different point on the frontier and the technology frontier may not shift uniformly. Rates of efficiency change might differ because some countries are changing policies, market incentives, etc. Country-to-country differences in the absolute level of Farrell-efficiency (Farrell, 1957), 1/D $\left(x^{t}, y^{t}\right)$, might arise because of fundamental differences in economic structure (policies, market incentives, human capital, etc), or because of systematic errors in measuring the variables. If for example, countries A and B are 
Table 2

Farrell-efficiency under constant returns-to-scale in selected years, by country

\begin{tabular}{lrrrr}
\hline Country & 1961 & 1970 & 1980 & 1984 \\
\hline Argentina & 1.00 & 1.00 & 1.00 & 1.00 \\
Brazil & 7.55 & 7.52 & 6.87 & 6.35 \\
Chile & 8.89 & 7.53 & 7.01 & 6.65 \\
Colombia & 8.25 & 5.77 & 5.09 & 4.83 \\
Dominican Rep. & 3.53 & 2.34 & 2.08 & 1.57 \\
Egypt & 1.00 & 1.00 & 1.00 & 1.00 \\
Ghana & 1.44 & 2.11 & 3.45 & 2.62 \\
Ivory Coast & 1.00 & 1.30 & 1.63 & 1.55 \\
Korea & 1.00 & 1.00 & 1.00 & 1.00 \\
Malaysia & 1.52 & 1.19 & 1.05 & 1.19 \\
Morocco & 9.20 & 6.05 & 8.98 & 6.37 \\
Pakistan & 2.01 & 3.01 & 3.09 & 2.64 \\
Philippines & 2.18 & 1.92 & 1.49 & 1.53 \\
Portugal & 1.64 & 1.41 & 1.72 & 1.60 \\
Sri Lanka & 1.78 & 2.05 & 1.86 & 1.83 \\
Thailand & 1.00 & 1.41 & 2.07 & 1.97 \\
Turkey & 4.55 & 3.89 & 3.03 & 2.79 \\
Zambia & 14.59 & 11.36 & 11.83 & 9.09 \\
\hline
\end{tabular}

identical in all respects except that a hectare of land in A is twice as productive as in B, then country B will appear to be Farrell-inefficient (Farrell, 1957). Year-toyear changes in efficiency, however, must be due to some other cause, as suggested above.

Average Malmquist indexes and components are reported in Tables 3-6, but it is useful first to consider the measures of Farrell-efficiency (Farrell, 1957) under constant returns-to-scale $\left(1 / D^{t}\left(x^{t}, y^{t}\right)\right.$, or OB/OA in Fig. 1) in Table 2. Argentina, Egypt and Korea were consistently Farrell-efficient (Farrell, 1957), indicating that those three countries define the frontier of technology in the vicinity of their observed input mixes. Argentina used land the most intensively relative to other inputs, with the least labor/ha (one fourth as much as the next-ranking) and the least fertilizer/ha (half the level of the next ranking.) Korea used land least intensively, using the most labor/ha, the most fertilizer/ha and second most tractors/ha but only an average amount of livestock/ha. Egypt, more representative of animal agriculture, used by far the most livestock/ha (nearly twice the level of the next ranking), but was similar to Korea in terms of other inputs per hectare.

Notice from Table 3 that two of these three frontier countries, Argentina and Korea, experienced declines in productivity during 1961-85. While this measure of performance was poorer during the first half of the period, it remained negative in the last half as well. Because they are frontier countries, this also means that the technological frontier in their vicinities was regressing. In Egypt however, produc- 


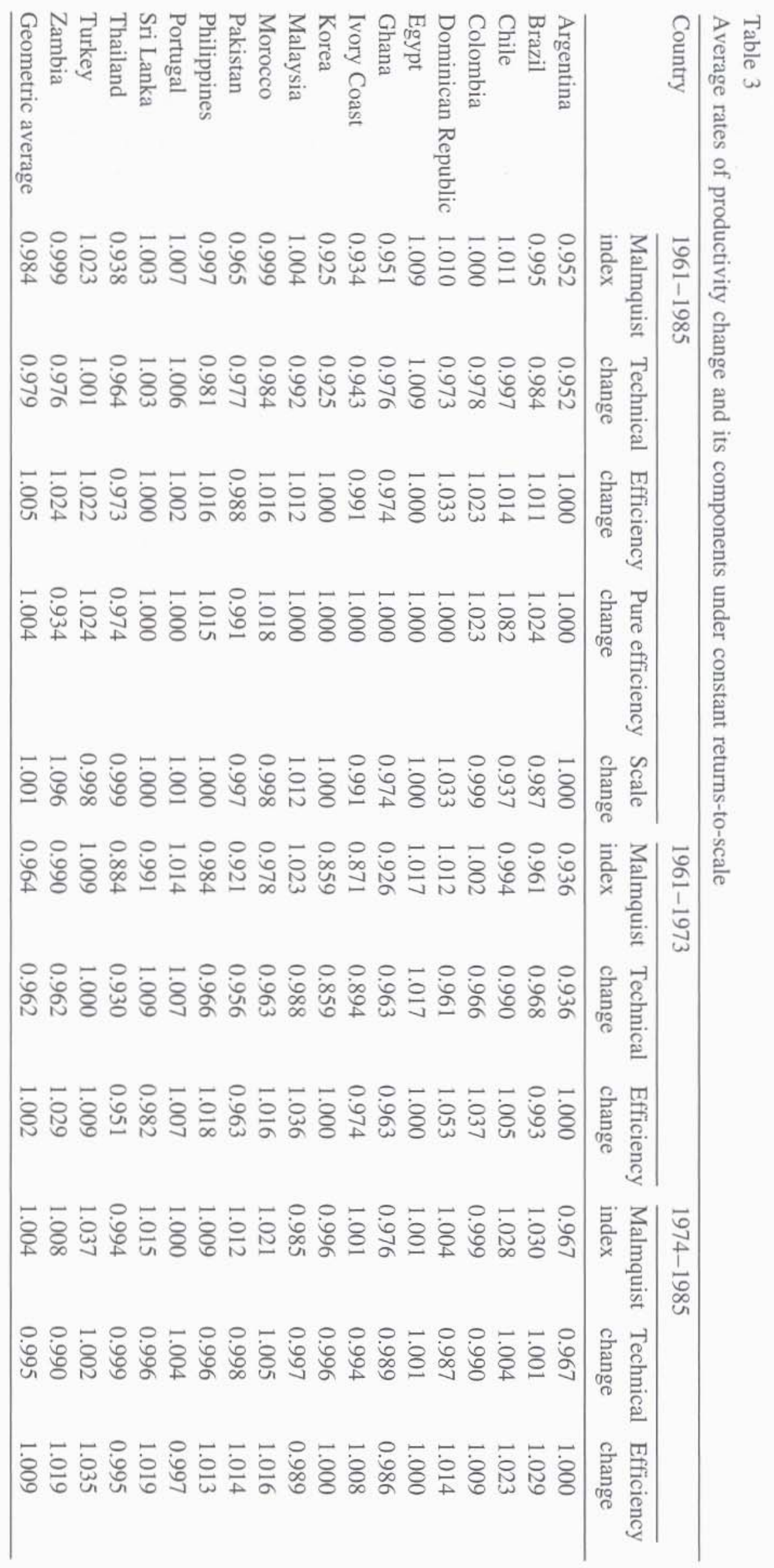


tivity and therefore the technological frontier in that vicinity advanced at the rate of $1.7 \%$ annually in the first half-period and $0.1 \%$ in the second, for an overall average of $0.9 \%$ annual gain. Because the countries defining the frontier declined in productivity on average, the weighted average rate of technical change for the entire set of countries was $-2.1 \%$ annually, with the regression being more severe in the first half of the period.

Average productivity performance (Malmquist indexes in the last row of Table 3) was a negative rate of $-3.6 \%$ annually in the first half-period, a positive rate of $0.4 \%$ in the second and $-1.6 \%$ for the entire period. Average productivity performance thus exceeded average technical change performance. As this suggests, the productivity performance in the three frontier countries was on average poorer than that in the nonfrontier countries $(-3.9 \%$ versus $-1.0 \%$, respectively, for the entire period). And since the frontier was in general regressing, improvements in a country's productivity will most likely be reflected as improvements in technical efficiency. Only Thailand, Zambia and Pakistan show an average deterioration in pure technical efficiency.

The country that had the best average rate of productivity gain was Turkey $(2.3 \%)$, but gains were also recorded by six other countries as well (Chile, Dominican Republic, Egypt, Portugal, Malaysia and Sri Lanka.) In addition, a number of other countries registered productivity gains in the second half-period, even though they had lost productivity during the first half (Brazil, Morocco, Philippines, Zambia and Ivory Coast.) Dismal productivity records in the first half by Korea, Ivory Coast and Thailand left them at the bottom of the rankings overall, even though they each had much better performances during the second half.

Half of the countries show scale efficiency improvements over the full period, half show none or negative scale efficiency changes, and the average rate of scale efficiency change is $0.1 \%$, or virtually zero. The average rate of change in scale efficiency rose from a negative $0.7 \%$ in $1961-73$ to a positive $0.1 \%$ in $1974-85$ (not reported in Table 3). ${ }^{18}$ There were no relationships discernable between the sizes of these agricultural sectors and the direction of change in scale efficiency. Since all except Portugal were increasing in size, this indicates that the technology exhibits many local scale optima, with some countries expanding toward them and other countries of similar size expanding away from them. These results offer little or no evidence for the hypothesis stated earlier that declines in measured productivity might have originated from a scale effect.

In Table 4 we compare the productivity results of the Malmquist index calculated in this study with those from a parametric production function previ-

\footnotetext{
${ }^{18}$ The average for the $1961-1973$ subperiod is 0.993 while that for $1974-1985$ is 1.001 . This seems to indicate that, on average, countries were moving toward optimal scale in the second period and away in the first.
} 
Table 4

Comparison of the Malmquist and Cobb-Douglas indexes of productivity change; 1961-1985

\begin{tabular}{lll}
\hline Country & Malmquist & Cobb-Douglas \\
\hline Argentina & 0.952 & 0.994 \\
Brazil & 0.995 & 0.973 \\
Chile & 1.011 & 1.008 \\
Colombia & 1.000 & 1.015 \\
Dominican Republic & 1.010 & 0.989 \\
Egypt & 1.009 & 0.997 \\
Ghana & 0.951 & 0.992 \\
Ivory Coast & 0.934 & 0.986 \\
Korea & 0.925 & 0.957 \\
Malaysia & 1.004 & 0.984 \\
Morocco & 0.999 & 1.010 \\
Pakistan & 0.965 & 0.971 \\
Philippines & 0.997 & 1.001 \\
Portugal & 1.007 & 0.974 \\
Sri Lanka & 1.003 & 0.988 \\
Thailand & 0.938 & 0.963 \\
Turkey & 1.023 & 0.976 \\
Zambia & 0.999 & 0.977 \\
Geometric average & 0.984 & 0.986
\end{tabular}

ously estimated using the same countries, though for slightly shorter time periods for most countries (Fulginiti and Perrin, 1993). In that study, the parameters of a Cobb-Douglas production function were specified as dependent on a set of technology-changing variables that included expected output and input prices, research stock, schooling and quality of land. The portion of the variation in output not explained by levels of traditional inputs, the Solow residual, is usually interpreted as productivity change. The average estimated productivity change derived in this manner is shown in the last column in Table 4. Across countries, that measure showed productivity to decline at the annual rate of $1.4 \%$, compared with the $1.6 \%$ rate of decline measured in the present study. On a country-bycountry basis, the econometric approach revealed only four of the 18 countries with positive rates of productivity growth (Chile, Colombia, Morocco and Philippines) whereas the Malmquist approach measured 10 positive rates. Two countries exhibited markedly worse Cobb- Douglas rankings as compared to Malmquist rankings (Portugal and Turkey) and two countries showed markedly better rankings (Argentina and Morocco). Where the two approaches indicated contrary directions of growth, however, the measured rates of change were very close to zero. Some of these differences could arise because of the shorter time periods included in the production function approach. The most significant result of the comparison is that agricultural productivity in these countries seems to have receded at an average rate of 1 to $2 \%$, and this result is robust with respect to measurement techniques. 
Table 5

Average rate of agricultural productivity change, 1961-1985, by 1986 per capita GNP classification

\begin{tabular}{ll}
\hline Income classification & Average Malmquist index \\
\hline Upper middle income $^{\mathrm{a}}$ & 0.976 \\
Low middle income $^{\mathrm{b}}$ & 0.991 \\
Low income $^{\mathrm{c}}$ & 0.979 \\
\hline
\end{tabular}

${ }^{\text {a} A r g e n t i n a, ~ B r a z i l, ~ K o r e a, ~ M a l a y s i a, ~ P o r t u g a l . ~}$

${ }^{\mathrm{b}}$ Chile, Colombia, Dominican Republic, Egypt, Ivory Coast, Morocco, Philippines, Thailand, Turkey.

${ }^{c}$ Ghana, Pakistan, Sri Lanka, Zambia.

It is perplexing why these countries should be showing declining productivity and technological regression during the very period when green-revolution seed varieties were spreading throughout many of these same countries. It is possible that the measurements are incorrect, but we have just shown above that these results hold under a nonparametric specification as well as the Cobb-Douglas parametric approach we used in an earlier study.

We conclude that agriculture in these countries in general has indeed decreased in productivity, which poses the question of why. It is beyond the scope of this paper to answer this question with any thoroughness, but some conjectures can be considered briefly. Could agricultural productivity be related in some way to the general level of wealth of the country? In Table 5 we group these countries according to three levels of per capita GNP: upper middle income, low middle income, and low income. ${ }^{19}$ Simple average agricultural productivity was declining in all groups, and there is no trend with income level. Upper middle income countries show the greatest drop (1.9 percent a year), followed by the low income countries (1.5 percent a year). Low middle income countries are the best performers with average agricultural productivity almost constant during the period.

Another conjecture is that productivity is affected by price policies. Our previous study of these countries suggested that price-depressing policies reduce productivity with an elasticity of 0.13 . We do not have measures of direct price policies for the 1961-85 period considered in the present study, but a series of World Bank studies (World Bank, 1988, also see Elisiana et al., 1993) provides annual measures of nominal price protection for periods that closely approximate that of this study (Table 1). ${ }^{20}$ In Table 6 we group the countries by this measure of the level of taxation of agriculture. In countries with a taxation level of more

\footnotetext{
${ }^{19}$ According to the World Bank classification in 1986 (reported in the 1988 World Development Report), GNP per capita in 1986 dollars is higher than $\$ 1800$ for upper middle income countries, between $\$ 450$ and $\$ 1800$ for low middle income countries and lower than $\$ 450$ for low income countries.

${ }^{20}$ Nominal price protection is defined as the gap between domestic and border prices after corrections are made for implicit protection of the nonagricultural sector and exchange rate policies.
} 
Table 6

Average rate of agricultural productivity change, 1961-1985, by level of taxation of the sector over the same general period ${ }^{\mathrm{a}}$

\begin{tabular}{ll}
\hline Level of taxation & Average Malmquist index \\
\hline Extremely taxed $^{\mathrm{b}}$ (more than 40\%) & 0.973 \\
Highly taxed & (30 to 39\%) \\
Taxed $^{\mathrm{d}}(0$ to $29 \%)$ & 0.987 \\
\hline
\end{tabular}

${ }^{\text {a }}$ Taxation levels are averages for each country for the years reported in Table 1.

b Argentina, Dominican Republic, Egypt, Ivory Coast, Pakistan, Sri Lanka, Thailand, Zambia.

${ }^{\mathrm{c} C}$ Colombia, Morocco, Philippines, Turkey.

${ }^{\mathrm{d}}$ Brazil, Chile, Ghana, Malaysia, Portugal.

than 40 percent, productivity decreased at a pace of 2.7 percent a year. In countries with taxes in the range of 30 to 39 percent, productivity declined at a slower rate of 1.3 percent, and for those countries in which agriculture was taxed little or not at all, measured productivity actually increased at the rate of 0.4 percent. These results tend to support in a general way our previous findings of the deleterious effects of price-depressing policies. The last figure, a productivity rate of 0.4 percent, happens to be close to the 0.7 percent calculated by Färe et al. (1994b) for the entire economies of a group of OECD countries. This suggests to us that the positive rate of 0.4 percent might indeed be more consistent with that which is achievable in an environment which does not tax producing sectors so heavily.

\section{Conclusions}

This paper examines changes in agricultural productivity in 18 developing countries over the period 1961-1985. We use the Malmquist index presented by Färe et al. $(1992,1994 a, b)$ to examine whether the results from that approach confirm results from other methods that have indicated declining agricultural productivity in LDCs. The Malmquist approach is less dependent on the parametric specification of the model, and it permits partitioning of productivity changes into efficiency and technical change components. The results confirmed previous findings that on average, agricultural productivity seems to have declined in these countries, especially during 1961-73, but also during 1974-85. This result was not uniform across countries, however, with four countries consistently showing gains in productivity, and nine others showing productivity losses.

Declining productivity seemed to characterize even those countries such as Pakistan and the Philippines, where green-revolution varieties of wheat and rice became widely adopted since the $1960 \mathrm{~s}$. The performance of these and other countries was better during the last half of the period than in the first, which suggests that positive productivity effects of the green revolution were not fully realized for some years after initial introduction. 
Partitioning of productivity changes into technical change and technical efficiency components revealed that three countries established the technically efficient frontier throughout the time period. It is possible that this result reflects systematic unmeasured differences in the quality of resources such as land and labor, but this hypothesis cannot be examined without more data on resource quality than we have available. Productivity in these frontier-establishing countries was in any case declining, which resulted in a measured regression of technology (negative technological change) and a measured improvement in technical efficiency among most other countries.

We conclude that the phenomenon of negative productivity trends indicated by previous studies has not been an artifact of the analytical methods used, since the general results are now supported by a variety of methods. The diversity of performance across countries, however, opens the possibility of discovering what factors contribute to productivity improvement in these countries. Though such analysis is beyond the scope of the present study, we did find that those countries that tax agriculture most heavily had the most negative rates of productivity change, consistent with previous results suggesting that price policies may be one important contributing factor.

\section{Acknowledgements}

The authors would like to thank S. Grosskopf for providing unpublished manuscripts and sample GAMS programs for calculating indexes.

\section{References}

Balk, B., 1993. Malmquist productivity indexes and Fisher ideal indexes: Comment. Econ. J. 103, $680-682$.

Ball, V., 1985. Output, input and productivity measurement. Am. J. Agric. Econ. 67, 475-486.

Bureau, R., Grosskopf, S., Färe, 1995. A Comparison of three nonparametric measures of productivity growth in European and United States Agriculture. J. Agric. Econ. 46, 309-326.

Capalbo, S., 1988. Measuring the components of aggregate productivity growth in U.S. agriculture. West. J. Agric. Econ. 13, 53-62.

Caves, D., Christensen, L., Diewert, D., 1982. The economic theory of index numbers and the measurement of input, output and productivity. Econometrica 50, 1393-1414.

Chavas, J.P., Cox, T., 1990. A nonparametric analysis of productivity: the case of U.S. and Japanese manufacturing. Am. Econ. Rev. 80, 450-464.

Diamond, P., McFadden, D., Rodriguez, M., 1978. Measurement of the elasticity of factor substitution and bias of technical change. In: Fuss, D., McFadden, D. (Eds.), Production Economics: A Dual Approach to Theory and Applications, vol. 2. North-Holland, Amsterdam, pp. 125-145.

Elisiana, J., Fulginiti, L., Perrin, R., 1993. Aggregate agricultural inputs and outputs in developing countries: a data set. Technical Report 93-TR 28, Center for Agricultural and Rural Development, Iowa State University, IA.

Färe, R., Grosskopf, S., 1992. Malmquist productivity indexes and Fisher ideal indexes. Econ. J. 102, 158-160. 
Färe, R., Grosskopf, S., Lindgren, B., Roos, P., 1992. Productivity changes in Swedish pharmacies 1980-1989: A nonparametric Malmquist approach. J. Product. Anal. 3, 85-101.

Färe, R., Grosskopf, S., Lovell, K., 1994a. Production Frontiers. Cambridge Univ. Press, Cambridge.

Färe, R., Grosskopf, S., Norris, M., Zhang, Z., 1994b. Productivity growth, technical progress and efficiency change in industrialized countries. Am. Econ. Rev. 84, 66-83.

Farrell, M.J., 1957. The measurement of productive efficiency. J. R. Stat. Soc. 120, 253-281.

Fulginiti, L., Perrin, R., 1993. Prices and productivity in agriculture. Rev. Econ. Stat. 75, 471-482.

Hayami, Y., Ruttan, V., 1970. Agricultural productivity differences among countries. Am. Econ. Rev. 40, 895-911.

Hayami, Y., Ruttan, V., 1985. Agricultural Development: An International Perspective. Johns Hopkins Univ. Press, Baltimore, MD.

Jorgenson, D., Gollop, F., Fraumeni, B., 1987. Productivity and U.S. Economic Growth. Harvard Univ. Press, Cambridge, MA.

Kawagoe, T., Hayami, Y., Ruttan, V., 1985. The intercountry agricultural production function and productivity differences among countries. J. Dev. Econ. 19, 113-132.

Kawagoe, T., Hayami, Y., 1985. An intercountry comparison of agricultural production efficiency. Am. J. Agric. Econ. 67, 87-92.

Lau, L., Yotopoulos, P., 1989. The meta-production function approach to technological change in world agriculture. J. Dev. Econ. 31, 241-269.

Malmquist, S., 1953. Index numbers and indifference surfaces. Trabajos de Estadistica 4, 209-242.

Sato, R., 1980. The impact of technical progress on the homotheticity of production functions. Rev. Econ. Stud. 47, 767-776.

Schultz, T.W., 1956. Reflections on agricultural production, output and supply. J. Farm Econ. 38, 613-631.

Trueblood, M., Ruttan, V., 1995. A comparison of multifactor productivity calculations of the U.S. agricultural sector. J. Prod. Anal. 6, 321-332.

World Bank, 1988. World Development Report. Oxford Univ. Press, Oxford. 